\title{
PERSPECTIVA DEL DERECHO DEL MEDIO AMBIENTE Y DE LAS POLÍTICAS AMBIENTALES DE LA UNIÓN EUROPEA \\ (PRIMER SEMESTRE 2021)
}

\author{
Pol Pallàs Secall \\ Investigador predoctoral FPI \\ Universitat de Barcelona \\ polpallas@ub.edu
}

SUMARIO: 1. Introducción. 2. Legislación y otros actos de la política europea del medioambiente. 2.1. Protección de la biodiversidad y la naturaleza. 2.2. Protección de las aguas. 2.3. Polución del aire y ruido. 2.4. Residuos y contaminantes. 2.5. Regulación sobre productos y etiqueta ecológica. 2.6. Cambio climático y deterioro de la capa de ozono. 2.7. Cuestiones transversales. 3. Otras políticas sectoriales de la Unión que afectan al medio ambiente. 3.1. Agricultura. 3.2. Pesca. 3.3. Energía. 3.4. Transporte. 3.5. Acción exterior. 3.6. Medidas de recuperación en el contexto de la pandemia de COVID-19.

\section{INTRODUCCIÓN}

Esta crónica comprende el período que va del 1 de octubre de 2020 a 28 de febrero de 2021. En ella se recoge toda la legislación medioambiental de las instituciones de la Unión Europea aprobada en este lapso de tiempo. Se prioriza la inclusión comentada de los instrumentos de derecho positivo ${ }^{1}$, pero también se incluyen documentos sin fuerza legal pero que informan al proceso legislativo, que se emiten en aplicación de alguna norma, o que expresan la posición de una institución respecto de una cuestión de orden medioambiental².

Se ha modificado la estructura respecto a anteriores ediciones de tal manera que se ordena la legislación y los demás actos comentados de forma temática en lugar de por tipo de instrumento. La primera parte incluye todos esos aspectos que forman

\footnotetext{
${ }^{1}$ Reglamentos, directivas, decisiones, reglamentos delegados, decisiones delegadas, reglamentos de ejecución, decisiones de ejecución, acuerdos internacionales y posiciones en organismos internacionales.

${ }^{2}$ Consultas públicas, comunicaciones e informes de la Comisión Europea, dictámenes del Comité de las Regiones y del Comité Económico y Social Europeo, procedimientos de infracción.
} 
parte del derecho ambiental estrictamente, tales como la protección de la biodiversidad, la regulación sobre residuos o la legislación climática. La segunda parte, en cambio, reúne la legislación relativa a otras políticas sectoriales de la Unión Europea que por su naturaleza afectan o están estrechamente vinculadas al medio ambiente y que normalmente tienen que cumplir requisitos de tipo ambiental o climático de acuerdo con el derecho comunitario europeo. En esta segunda parte, por tanto, no ha regido un criterio de exhaustividad, ya que se han reunido solo aquellos actos con relevancia ambiental.

El criterio temporal que se ha seguido para la inclusión en esta crónica de las normas y otros actos de la Unión es la fecha de su aprobación o fecha de documento. Es decir, no se han incluido las normas de derecho de la Unión Europea por otras consideraciones temporales, tales como la fecha de publicación o su entrada en vigor.

\section{LEGISLACIÓN Y OTROS ACTOS DE LA POLÍTICA EUROPEA DEL MEDIOAMBIENTE POR AREAS TEMÁTICAS}

\subsection{Protección de la biodiversidad y la naturaleza}

En el ámbito de la protección de los hábitats y la protección de la biodiversidad destaca en primer lugar la adopción de siete decisiones de ejecución que actualizan la lista de lugares de importancia comunitaria para cada una de las regiones biogeográficas europeas a excepción de la estépica, con lo que se añaden una serie de espacios a la red natura 2000 a partir de las propuestas de los Estados miembros:

- Decisión de Ejecución (UE) 2021/159 de la Comisión de 21 de enero de 2021 por la que se adopta la decimocuarta lista actualizada de lugares de importancia comunitaria de la región biogeográfica mediterránea [notificada con el número C(2021) 19]

- Decisión de Ejecución (UE) 2021/165 de la Comisión de 21 de enero de 2021 por la que se adopta la decimocuarta lista actualizada de lugares de importancia comunitaria de la región biogeográfica alpina [notificada con el número C(2021) 143]

- Decisión de Ejecución (UE) 2021/164 de la Comisión de 21 de enero de 2021 por la que se adopta la sexta lista actualizada de lugares de importancia comunitaria de la región biogeográfica del mar Negro [notificada con el número C(2021) 24] 
- Decisión de Ejecución (UE) 2021/158 de la Comisión de 21 de enero de 2021 por la que se adopta la decimocuarta lista actualizada de lugares de importancia comunitaria de la región biogeográfica boreal [notificada con el número C(2021) 18]

- Decisión de Ejecución (UE) 2021/160 de la Comisión de 21 de enero de 2021 por la que se adopta la duodécima lista actualizada de lugares de importancia comunitaria de la región biogeográfica panónica [notificada con el número C(2021) 20]

- Decisión de Ejecución (UE) 2021/163 de la Comisión de 21 de enero de 2021 por la que se adopta la decimocuarta lista actualizada de lugares de importancia comunitaria de la región biogeográfica atlántica [notificada con el número C(2021) 23]

- Decisión de Ejecución (UE) 2021/162 de la Comisión de 21 de enero de 2021 por la que se adopta la novena lista actualizada de lugares de importancia comunitaria de la región biogeográfica macaronésica [notificada con el número C(2021) 22]

- Decisión de Ejecución (UE) 2021/161 de la Comisión de 21 de enero de 2021 por la que se adopta la decimocuarta lista actualizada de lugares de importancia comunitaria de la región biogeográfica continental [notificada con el número C(2021) 21]

Se aprobó la Decisión (UE) 2020/1830 del Consejo de 27 de noviembre de 2020 sobre la posición que deberá adoptarse en nombre de la Unión Europea en la cuadragésima reunión del Comité Permanente del Convenio relativo a la conservación de la vida silvestre y del medio natural de Europa (Convenio de Berna). Mediante este instrumento, el Consejo decidió proponer el aplazamiento de la votación sobre la inclusión de cláusulas financieras y en apoyar el establecimiento de un fondo de apoyo para la aplicación del Convenio.

En el ámbito del bienestar animal y, en concreto, de la regulación del comercio de productos derivados de la foca se aprobó la Decisión de Ejecución (UE) 2020/2125 de la Comisión de 16 de diciembre de 2020 por la que se reconoce al Gobierno de Nunavut como organismo autorizado para expedir documentos acreditativos del cumplimiento del Reglamento (CE) n.o 1007/2009 del Parlamento Europeo y del Consejo para la comercialización de productos derivados de la foca en el mercado de la Unión. La medida carece de valor substantivo, pues el gobierno de Nunavut, un territorio canadiense, ya era la autoridad reconocida a los efectos del Reglamento 1007/2009, pero pidió un cambió del nombre identificativo respondiendo a una reestructuración interna de su administración. 
Durante el período comprendido en esta crónica se emitió el Informe de la Comisión al Parlamento Europeo, al Consejo y al Comité Económico y Social Europeo. Estado de la naturaleza en la Unión Europea Informe sobre el estado y las tendencias de los tipos de hábitats y las especies regulados por las Directivas de Aves y de Hábitats durante el período 2013-2018. El documento concluye que los avances realizados en la aplicación de las dos Directivas son claramente insuficientes. La designación de espacios de la Red Natura 2000 es incompleto, así como el establecimiento de medidas de conservación adecuados para estos hábitats. Señala que los requisitos de protección de la naturaleza no se han integrado de forma suficientemente eficaz en las políticas de uso del suelo y del agua por tal de vencer los efectos perjudiciales de la agricultura y la explotación forestal. También apunta la falta de acuerdo para las medidas de protección de varios espacios marinos de la Red Natura 2000, así como los crecientes peligros para los hábitats y la fauna silvestre que entraña el cambio climático. Por último, el informe recalca el potencial de la Estrategia sobre biodiversidad para 2030, que ya comentamos en la anterior crónica, pero también el cambio drástico requerido en la protección de la naturaleza para que se puedan cumplir los objetivos establecidos en la misma. La próxima evaluación del estado de la naturaleza de la Unión está prevista para 2026.

Se emitió, asimismo, el Dictamen del Comité de las Regiones - Ciudades y regiones enfocadas a la biodiversidad más allá de 2020 en la COP15 del CDB de las Naciones Unidas y en la estrategia de la UE sobre biodiversidad para 2030. El Comité considera que es necesario coordinar las medidas de conservación de la naturaleza a escala local y en ese sentido expresa su compromiso con el desarrollo de corredores ecológicos que forman parte de la Red Transeuropea de Espacios Naturales. Considera que para alcanzar los objetivos establecidos en Pacto Verde Europeo y la Estrategia de la UE sobre la biodiversidad es necesaria la implicación y el trabajo conjunto de las regiones y los entes locales.

Cabe mencionar que se abrieron a consulta pública tres iniciativas en el ámbito de la protección de la naturaleza y la biodiversidad. Entre el 11 de enero de 2020 y el 5 de abril de 2021 los interesados pudieron dar su opinión para la elaboración de un informe por parte de la Comisión en la consulta pública para la "Evaluación de la Estrategia sobre biodiversidad de la UE para 2020". 
En el mismo período que la anterior estuvo abierta a consulta pública la iniciativa "Proteger la biodiversidad: objetivos de restauración de la naturaleza en la Estrategia de la biodiversidad para 2030. El objetiva de esta iniciativa de Reglamento es el establecimiento de unos objetivos de restauración de la naturaleza vinculantes y medibles mediante evaluaciones de impacto ambiental.

Estrechamente relacionada con las anteriores, también se abrió a consulta pública el 25 de enero y hasta el 19 de abril la iniciativa por una comunicación de la Comisión "Bosques: nueva estrategia de la UE". Esta se basará plenamente en la Estrategia sobre biodiversidad para 2030 con el objetivo de asegurar unos bosques sanos que contribuyan a la biodiversidad, a los objetivos climáticos y a la economía circular. También contendrá una perspectiva de acción exterior en cuanto pretende abarcar los bosques de otras regiones del mundo aún no cubiertos por medidas de protección, restauración y gestión sostenible.

Entre el 2 de febrero y el 27 de abril estuvo abierta a consulta pública la iniciativa "Suelos sanos - nueva estrategia de la UE para la protección del suelo" para la elaboración de una comunicación de la Comisión. Esta pretende actualizar la estrategia de protección de los suelos en el marco de la Estrategia de la UE sobre Biodiversidad para 2030 con el objetivo de "proteger la fertilidad del suelo, reducir la erosión y el sellado, aumentar la materia orgánica, determinar los terrenos contaminados, restaurar los suelos degradados y definir lo que se entiende por «buen estado ecológico» de los suelos".

Antes de terminar este apartado hay que señalar que la Comisión decidió llevar al Tribunal de Justicia de la Unión Europea a Alemania por incumplir los plazos en relación a los espacios catalogados en la Red Natura 2000 como Zonas Especiales de Conservación (ZECs). Según la Comisión, Alemania debería haber designado más ZECs que las actuales y establecido objetivos y medidas de conservación adecuadas para la fauna y la flora silvestre en todas ellas. Además, la Comisión considera que los objetivos ya establecidos no son suficientemente cuantificables y medibles, con lo que entiende que ha habido una falta general y persistente de establecer de forma efectiva y adecuada los objetivos para los 4606 espacios de importancia comunitaria del territorio alemán. El plazo para realizar tales acciones expiró hace más de diez años en algunos casos. 


\subsection{Protección de las aguas}

En el ámbito de la protección de la aguas se ha aprobado una relevante versión refundida de la directiva sobre aguas destinadas al consumo humano: Directiva (UE) 2020/2184 del Parlamento Europeo y del Consejo de 16 de diciembre de 2020 relativa a la calidad de las aguas destinadas al consumo humano (versión refundida) (Texto pertinente a efectos del EEE). Este instrumento actualiza los parámetros y los valores de salubridad de las aguas de acuerdo con los nuevos conocimientos científicos y establece un método basado en factores de riesgo para la evaluación del agua para consumo humano en toda la cadena de suministro. También introduce ciertas medidas en relación a los alteradores endocrinos y los microplásticos, sobre los cuales la Comisión deberá aprobar decisiones delegadas para complementar la presente directiva.

Vinculado a dicha directiva, se emitió la Comunicación de la Comisión al Parlamento Europeo con arreglo al artículo 294, apartado 6, del Tratado de Funcionamiento de la Unión Europea sobre la posición del Consejo sobre la adopción de la Directiva del Parlamento Europeo y del Consejo relativa a la calidad de las aguas destinadas al consumo humano (versión refundida). En ella la Comisión expresa la general aceptación de la propuesta del Consejo, pero recalca algunas inconformidades como la falta de acuerdo entre los dos colegisladores para la actualización del Anexo II de la directiva relativo al control de las aguas. Según la Comisión habría sido necesario actualizar los requisitos de control para adaptarlos a los avances científicos y técnicos. Por último, en relación a la normativa sobre protección de las aguas, hay que mencionar el recurso de la Comisión contra Eslovenia delante del Tribunal de Justicia de la Unión Europea por el incumplimiento de la normativa sobre tratamiento de aguas urbanas residuales. Eslovenia debería haber cumplido con la Directiva 91/271/EEC sobre Tratamiento de Aguas Urbanas Residuales desde 2016, pero cuatro aglomeraciones urbanas eslovenas aún no alcanzan los parámetros establecidos debido a que sus aguas residuales no reciben el tratamiento adecuada antes de ser vertidas.

\subsection{Polución del aire y ruido}


En el ámbito de la polución del aire y el ruido no se aprobó ninguna norma jurídica durante el período observado en esta crónica, pero sí encontramos otro tipo de actos y documentos relevantes. El Informe de la Comisión al Parlamento Europeo, al Consejo, al Comité Económico y Social Europeo y al Comité de las Regiones: segunda perspectiva sobre el paquete «aire limpio» resalta el grave impacto para la salud humana y los ecosistemas que tiene la polución del aire. Este es el segundo informe que analiza los resultados de la Directiva relativa a las reducciones de las emisiones nacionales (Directiva TNE) en vistas de alcanzar el objetivo de reducir a la mitad el impacto en la salud de la polución del aire en 2030 en comparación con el 2005. El informe concluye que los Estados ya han adoptado las medidas suficientes para alcanzar este objetivo, pero afirma también que hay un déficit en su aplicación y que hace falta un mayor esfuerzo en ese sentido. Considera que otras políticas de la Unión como la acción por el clima o la PAC contribuyen de forma sinérgica a la reducción de la polución en el aire, aunque no son suficientes por ellas mismas por lo que requiere de un trabajo específico en este sentido.

Por tal de elaborar otra comunicación de la Comisión, entre el 11 de noviembre de 2020 y el 10 de febrero de 2021 estuvo abierta a consulta pública la iniciativa "Hacia una contaminación cero del aire, el agua y el suelo: plan de acción de la UE”. Su objetivo es elaborar una estrategia para mejorar la prevención, la reducción, el control y la información sobre la contaminación, así como integrar este objetivo en las demás políticas de la Unión y evitar que el crecimiento de la economía vaya en su detrimento.

En línea con el contenido de este informe, la Comisión ha decidido llevar ante el Tribunal de Justicia de la Unión Europea a cuatro Estados miembros por incumplimiento de la normativa sobre calidad del aire (Directiva 2008/50/EC). En el caso de Francia la Comisión afirma que se han rebasado los límites de forma ininterrumpida en París y Martinica desde 2005, cuando empezaron a ser obligatorios los límites para partículas PM10. Esta es la segunda vez que la Comisión abre un recurso por esta cuestión contra Francia, ya que en 2019 el Tribunal consideró que se superaban los límites de NO2 en 12 aglomeraciones francesas.

Grecia por su parte ha superado los límites de partículas PM10 en la aglomeración de Tesalónica, de la misma manera que Eslovaquia, que ha superado los límites de PM10 entre 2005 y 2019 en la región de Banska Bystrica y en Košice. La Comisión 
considera que las medidas emprendidas por ambos países son insuficientes y por eso decide llevar el caso ante el Tribunal de Justicia de la Unión Europea.

En cuarto lugar, la Comisión considera que Bulgaria no solo no ha tomado las medidas para reducir los niveles de PM10 por debajo del umbral, sino que también ha incumplido una primera sentencia del Tribunal que la obligaba a tomar medidas urgentes en ese sentido, por lo que se enfrenta a penalizaciones financieras hasta que esta situación no se corrija. En el caso de Bulgaria los excesos por encima del límite para partículas PM10 son especialmente altas, con más de 90 días al año superándolo por 2,5 veces.

En cuanto a la normativa de ruido hay que hacer referencia a la decisión de la Comisión de llevar a Polonia ante el Tribunal de Justicia de la Unión Europea por incumplimiento de la Directiva sobre ruido (2002/49/EC). De acuerdo con esta directiva los Estados miembros tienen que adoptar planes de acción, aunque no se superen los límites de ruido, pero la ley polaca no refleja dicha obligación. Es por eso que 20 secciones ferroviarias y 290 carreteras principales aún no tienen un plan de acción de este tipo a pesar de que la fecha límite expiró hace tiempo.

\subsection{Residuos y contaminantes}

Durante el período de tiempo analizado en esta crónica se han aprobado dos reglamentos relativos a la clausura de centrales nucleares con provisiones para la gestión de sus residuos: El Reglamento (Euratom) 2021/100 del Consejo de 25 de enero de 2021 por el que se establece un programa financiero específico para la clausura de instalaciones nucleares y la gestión de residuos radiactivos y se deroga el Reglamento (Euratom) n.o 1368/2013 del Consejo, prevé la clausura de reactores nucleares y otras instalaciones nucleares de centrales de Bulgaria, Eslovaquia, Bélgica, Alemania y Países Bajos; también se adoptó el Reglamento (UE) 2021/101 del Consejo de 25 de enero de 2021 por el que se establece el programa de ayuda a la clausura nuclear de la central nuclear de Ignalina en Lituania y se deroga el Reglamento (UE) n.o 1369/2013. Este prevé la clausura integral de este central nuclear y la difusión de los conocimientos generados en el proceso mediante el Centro Común de Investigación. 
En relación a otro tipo de residuos, se aprobó la Decisión de Ejecución (UE) 2021/19 de la Comisión de 18 de diciembre de 2020 por la que se establece una metodología común y un formato para la comunicación de datos sobre la reutilización de conformidad con la Directiva 2008/98/CE del Parlamento Europeo y del Consejo [notificada con el número C(2020) 8976] (Texto pertinente a efectos del EEE). Se provee una plantilla unificada para la comunicación de los datos, así como algunas indicaciones de los requisitos que estos han de cumplir.

Respecto a otro tipo de residuos diferente de los dos anteriores, los productos de plástico de un solo uso, se ha adoptado el Reglamento de Ejecución (UE) 2020/2151 de la Comisión de 17 de diciembre de 2020 por el que se establecen normas sobre las especificaciones armonizadas del marcado de los productos de plástico de un solo uso enumerados en la parte D del anexo de la Directiva (UE) 2019/904 del Parlamento Europeo y del Consejo, relativa a la reducción del impacto de determinados productos de plástico en el medio ambiente (Texto pertinente a efectos del EEE). Establece unos criterios armonizados de marcado dirigido a los consumidores para los siguientes productos: compresas, tampones higiénicos, aplicadores de tampones, toallitas húmedas, productos del tabaco con filtros, filtros comercializados para utilizarse en combinación con productos del tabaco y vasos de bebidas.

Se aprobaron tres instrumentos vinculados Convenio de Basilea sobre el control de los movimientos transfronterizos de los desechos peligrosos y su eliminación: Decisión (UE) 2020/1829 del Consejo de 24 de noviembre de 2020 sobre la presentación, en nombre de la Unión Europea, de propuestas de modificación del anexo IV, así como de determinadas entradas de los anexos II y IX, del Convenio de Basilea sobre el control de los movimientos transfronterizos de los desechos peligrosos y su eliminación, para su consideración en la decimoquinta reunión de la Conferencia de las Partes, y sobre la posición que debe adoptarse en nombre de la Unión Europea en dicha reunión en relación con las propuestas de modificación por otras Partes del anexo IV y determinadas entradas de los anexos II, VIII y IX de dicho Convenio. Se establece la posición que ha de adoptar la Unión en la Conferencia de las Partes prevista para julio de 2021 en relación a ciertas propuestas mejorar el control sobre envió transfronterizo ilícito de desechos peligrosos de recuperación y de no recuperación. 
El Reglamento Delegado (UE) 2020/2174 de la Comisión de 19 de octubre de 2020 por el que se modifican los anexos IC, III, IIIA, IV, V, VII y VIII del Reglamento (CE) n.o 1013/2006 del Parlamento Europeo y del Consejo, relativo a los traslados de residuos (Texto pertinente a efectos del EEE), por su lado, tiene por objeto la actualización de la normativa europea en esta cuestión a raíz de las modificaciones técnicas introducidas por la Conferencia de las Partes de la Convención de Basilea en relación a las importaciones y exportaciones de desechos plásticos no peligrosos.

Por último, se aprobó la lista anual de instalaciones de reciclado de buques mediante la Decisión de Ejecución (UE) 2020/1675 de la Comisión de 11 de noviembre de 2020 por la que se modifica la Decisión de Ejecución (UE) 2016/2323, por la que se establece la lista europea de instalaciones de reciclado de buques con arreglo al Reglamento (UE) n.o 1257/2013 del Parlamento Europeo y del Consejo (Texto pertinente a efectos del EEE). En esta lista se recogen las instalaciones de reciclado de buques autorizadas, tanto las que lo son por primera vez como aquellas a las que se les ha renovado la autorización. Incluye aquellas instalaciones de reciclado de buques de Reino Unido a las que se les renovó la autorización antes de que finalizara el período transitorio en diciembre de 2020, mientras que las instalaciones cuya autorización finalizó después de esta fecha no pudieron ser renovadas y ya no aparecen en la lista.

Respecto a la regulación sobre contaminantes se aprobaron dos reglamentos delegados en relación a la normativa sobre contaminantes orgánicos persistentes que añaden ciertas modificaciones técnicas:

- Reglamento Delegado (UE) 2021/115 de la Comisión de 27 de noviembre de 2020 por el que se modifica el anexo I del Reglamento (UE) 2019/1021 del Parlamento Europeo y del Consejo en lo que respecta al ácido perfluorooctanoico (PFOA), sus sales y las sustancias afines al PFOA (Texto pertinente a efectos del EEE).

- Reglamento Delegado (UE) 2021/277 de la Comisión de 16 de diciembre de 2020 por el que se modifica el anexo I del Reglamento (UE) 2019/1021 del Parlamento Europeo y del Consejo, sobre contaminantes orgánicos persistentes, por lo que respecta al pentaclorofenol y sus sales y ésteres (Texto pertinente a efectos del EEE).

Sobre la contaminación marina se adoptó la Decisión (UE) 2021/176 del Consejo de 5 de febrero de 2021 por la que se aprueban las enmiendas del Acuerdo sobre la 
cooperación en materia de lucha contra la contaminación del Mar del Norte por hidrocarburos y otras sustancias peligrosas (Acuerdo de Bonn) en lo referente a la ampliación del ámbito de aplicación de dicho Acuerdo y la adhesión del Reino de España al mismo.

En el área de la prevención de accidentes se aprobó una decisión de ejecución relevante por el impacto ambiental de los accidentes previstos: Decisión de Ejecución (UE) 2021/88 de la Comisión de 26 de enero de 2021 por la que se modifica la Decisión de Ejecución (UE) 2019/570 en lo que respecta a las capacidades de rescEU en el ámbito de los incidentes químicos, biológicos, radiológicos y nucleares [notificada con el número C(2021) 313] (Texto pertinente a efectos del EEE). Este acto pretende incrementar las capacidades de descontaminación incrementando la acumulación de recursos y provisiones para este propósito.

Hay que referirse, aunque solo sea a modo enumerativo, a la regulación sobre registro, evaluación, autorización y restricción de sustancias y preparados químicos, la normativa REACH, por el potencial impacto en el medio ambiente. Se han aprobado tres reglamentos y una decisión de ejecución en este campo:

- Reglamento (UE) 2021/57 de la Comisión de 25 de enero de 2021 que modifica, por lo que respecta al plomo en la munición de las armas de fuego utilizadas en los humedales o en sus inmediaciones, el anexo XVII del Reglamento (CE) n.o 1907/2006 del Parlamento Europeo y del Consejo, relativo al registro, la evaluación, la autorización y la restricción de las sustancias y preparados químicos (REACH) (Texto pertinente a efectos del EEE).

- Reglamento (UE) 2020/2096 de la Comisión de 15 de diciembre de 2020 por el que se modifica el anexo XVII del Reglamento (CE) n.o 1907/2006 del Parlamento Europeo y del Consejo, relativo al registro, la evaluación, la autorización y la restricción de las sustancias y mezclas químicas (REACH), en lo que se refiere a las sustancias carcinógenas, mutágenas o tóxicas para la reproducción (sustancias CMR), los productos contemplados por el Reglamento (UE) 2017/745 del Parlamento Europeo y del Consejo, los contaminantes orgánicos persistentes, determinadas sustancias o mezclas líquidas, el nonilfenol y los métodos de ensayo para los colorantes azoicos (Texto pertinente a efectos del EEE). 
- Reglamento (UE) 2020/2081 de la Comisión de 14 de diciembre de 2020 que modifica el anexo XVII del Reglamento (CE) n.o 1907/2006 del Parlamento Europeo y del Consejo, relativo al registro, la evaluación, la autorización y la restricción de las sustancias y mezclas químicas (REACH), en lo que respecta a las sustancias contenidas en las tintas para tatuaje o maquillaje permanente (Texto pertinente a efectos del EEE).

- Decisión de Ejecución (UE) 2020/2182 de la Comisión de 18 de diciembre de 2020 por la que se establece la respuesta definitiva, en nombre de la Unión, sobre la futura importación de determinados productos químicos de conformidad con el Reglamento (UE) n.o 649/2012 del Parlamento Europeo y del Consejo y se modifica la Decisión de Ejecución de la Comisión de 15 de mayo de 2014 por la que se adoptan decisiones de importación de la Unión relativas a determinados productos químicos con arreglo a ese Reglamento [Notificada con el número C(2020) 8977].

También en relación a la normativa $\mathrm{REACH}$ se emitió la Comunicación de la Comisión al Parlamento Europeo, al Consejo, al Comité Económico y Social Europeo y al Comité de las Regiones: Estrategia de sostenibilidad para las sustancias químicas Hacia un entorno sin sustancias tóxicas. Esta estrategia pretende iniciar un proceso para la mejora de la normativa REACH desde un punto de vista de salud humana, pero también de sostenibilidad ambiental que forme de las iniciativas tomadas en el marco del Pacto Verde Europeo, por lo que hay que esperar que en los próximos años se desarrolle legislativamente este objetivo político.

Para terminar este apartado hay que hacer referencia a la iniciativa "Utilización de lodos de depuradora en la agricultura: evaluación", que estuvo abierta a consulta pública entre el 20 de noviembre de 2020 y el 5 de marzo de 2021. Tenía por objetivo recabar la opinión de los grupos de interés en este tema por tal de revisar el funcionamiento de la Directiva 86/278, que se presume no ajustada a las necesidades actuales por no incluir contaminantes emergentes tales como los productos farmacéuticos o los microplásticos.

\subsection{Regulación sobre productos y etiqueta ecológica}

El ámbito del diseño ecológico de productos ha generado varios actos legislativos durante este período. Cabe destacar en primer lugar la aprobación del Reglamento 
de Ejecución (UE) 2021/279 de la Comisión de 22 de febrero de 2021 por el que se establecen normas detalladas para ejecutar el Reglamento (UE) 2018/848 del Parlamento Europeo y del Consejo en lo relativo a los controles y otras medidas que garanticen la trazabilidad y el cumplimiento de lo dispuesto en materia de producción ecológica y etiquetado de los productos ecológicos (Texto pertinente a efectos del EEE). Entre los aspectos definidos por este reglamento sobre el control sobre la producción y etiquetado de los productos ecológicos encontramos: los criterios de creación de un Sistema de Controles Internos (SCl) tales como el número de operadores que deben formarlo, los requisitos que debe cumplir la investigación de un incumplimiento, la documentación y el registro que deben llevar los grupos de operadores, el número mínimo de controles que deben realizarse y diferentes disposiciones sobre el intercambio de información.

Los demás reglamentos, reglamentos de ejecución o reglamentos delegados aprobados en este ámbito no merecen mayor comentario por su carácter meramente técnico o por introducir simples cambios temporales:

- Reglamento de Ejecución (UE) 2020/2042 de la Comisión de 11 de diciembre de 2020 que modifica el Reglamento de Ejecución (UE) 2020/464 en lo que respecta a su fecha de aplicación y a otras fechas pertinentes para la aplicación del Reglamento (UE) 2018/848 del Parlamento Europeo y del Consejo sobre producción ecológica (Texto pertinente a efectos del EEE).

- Reglamento de Ejecución (UE) 2020/1667 de la Comisión de 10 de noviembre de 2020 que modifica el Reglamento de Ejecución (UE) 2020/977 en lo que se refiere al período de aplicación de las medidas temporales en relación con los controles de la producción de productos ecológicos (Texto pertinente a efectos del EEE).

- Reglamento de Ejecución (UE) 2020/2196 de la Comisión de 17 de diciembre de 2020 que modifica el Reglamento (CE) n.o 1235/2008, por el que se establecen las disposiciones de aplicación del Reglamento (CE) n.o 834/2007 del Consejo en lo que se refiere a las importaciones de productos ecológicos procedentes de terceros países (Texto pertinente a efectos del EEE).

- Reglamento de Ejecución (UE) 2021/181 de la Comisión de 15 de febrero de 2021 que modifica el Reglamento (CE) n.o 889/2008, por el que se establecen disposiciones de aplicación del Reglamento (CE) n.o 834/2007 del Consejo sobre 
producción y etiquetado de los productos ecológicos, con respecto a la producción ecológica, su etiquetado y su control (Texto pertinente a efectos del EEE).

- Reglamento Delegado (UE) 2021/269 de la Comisión de 4 de diciembre de 2020 por el que se modifica el Reglamento Delegado (UE) 2020/427 en lo que atañe a la fecha de aplicación de las modificaciones de determinadas normas de producción aplicables a los productos ecológicos que figuran en el anexo II del Reglamento (UE) 2018/848 del Parlamento Europeo y del Consejo (Texto pertinente a efectos del EEE).

- Reglamento (UE) 2021/341 de la Comisión de 23 de febrero de 2021 por el que se modifican los Reglamentos (UE) 2019/424, (UE) 2019/1781, (UE) 2019/2019, (UE) 2019/2020, (UE) 2019/2021, (UE) 2019/2022, (UE) 2019/2023 y (UE) 2019/2024 en lo relativo a los requisitos de diseño ecológico aplicables a servidores y productos de almacenamiento de datos, motores eléctricos y controladores de velocidad variable, aparatos de refrigeración, fuentes luminosas y mecanismos de control independientes, pantallas electrónicas, lavavajillas domésticos, lavadoras domésticas y lavadoras-secadoras domésticas y aparatos de refrigeración con función de venta directa (Texto pertinente a efectos del EEE).

Respecto a la regulación del etiquetado de los productos ecológicos se han aprobado un reglamento y tres decisiones de tipo técnico que recogemos a modo enumerativo:

- Reglamento (UE) 2020/1693 del Parlamento Europeo y del Consejo de 11 de noviembre de 2020 por el que se modifica el Reglamento (UE) 2018/848, sobre producción ecológica y etiquetado de los productos ecológicos, en lo que respecta a la fecha de aplicación y a otras fechas que en él se mencionan (Texto pertinente a efectos del EEE).

- Decisión (UE) 2020/1803 de la Comisión de 27 de noviembre de 2020 por la que se establecen los criterios de la etiqueta ecológica de la UE aplicables a la categoría de productos «papel impreso, papel para escritorio y bolsas de papel» [notificada con el número $\mathrm{C}(2020)$ 8155] (Texto pertinente a efectos del EEE).

- Decisión (UE) 2020/1804 de la Comisión de 27 de noviembre de 2020 por la que se establecen los criterios para la concesión de la etiqueta ecológica de la UE a las pantallas electrónicas [notificada con el número C(2020) 8156] (Texto pertinente a efectos del EEE). 
- Decisión (UE) 2020/1805 de la Comisión de 27 de noviembre de 2020 por la que se modifican las Decisiones 2014/350/UE y (UE) 2016/1349 para prorrogar el período de validez de los criterios ecológicos para la concesión de la etiqueta ecológica de la UE a los productos textiles y al calzado, así como los requisitos de evaluación y verificación correspondientes [notificada con el número $C(2020)$ 8152] (Texto pertinente a efectos del EEE).

\subsection{Cambio climático y deterioro de la capa de ozono}

Durante el período de tiempo analizado aquí se ha emitido una comunicación de carácter marcadamente político en el ámbito de la política climática. Se trata de la Comunicación de la Comisión al Parlamento Europeo, al Consejo, al Comité Económico y Social Europeo y al Comité de las Regiones: Pacto Europeo por el Clima. Este documento presenta la propuesta de la Comisión para implicar a todos los actores de la Unión a todos los niveles y en todos los sectores para alcanzar los objetivos climáticos fijados en el Pacto Verde Europeo. Pone especial énfasis en los jóvenes y en las actividades de concienciación, pero también en reforzar acciones ya en marcha como los edificios ecológicos, la movilidad sostenible y el desarrollo de un sector económico de las energías renovables que se traduzca en empleos verdes.

Aunque aquí no lo podemos examinar de forma exhaustiva, hay que hacer mención del Informe de la Comisión al parlamento Europeo, al Consejo, al Comité Económico y Social Europeo y al Comité de las Regiones - Iniciar el viaje hacia una Europa climáticamente neutra de aquí a 2050: Informe de situación de la Acción por el Clima de la UE correspondiente a 2020. Pone de manifiesto que el volumen de emisiones de efecto invernadero descendió durante el 2019 en más de un 3\% a pesar de que la economía siguió creciendo. También manifiesta que los Estados miembros cumplieron los límites de emisiones en el período 2013-2017, aunque fuese mediante el balance mediante la compra de derechos de emisión. Hay que recalcar que la financiación climática se ha mantenido estable desde 2016 en cuanto a porcentaje sobre el presupuesto de la UE, lo cual es incoherente con el incremento de las presiones climáticas a que el mismo informe hace referencia. El informe sigue por exponer la labor de la Unión en el ámbito climático por lo que respecta a la adaptación 
climática, el régimen de comercio de derechos de emisiones y el uso del suelo entre otros aspectos.

También se publicó, como es de obligación anualmente para la Comisión, el Informe de la Comisión al Parlamento Europeo, al Consejo, al Comité Económico y Social Europeo y al Comité de la Regiones: Informe de 2020 sobre el estado de la Unión de la Energía, de conformidad con el Reglamento (UE) 2018/1999, sobre la gobernanza de la Unión de la Energía y de la Acción por el Clima. El informe destaca que en términos globales se han superado los objetivos para 2020 en cuanto a la cuota de energía renovable en el cómputo total de consumo bruto de energía. El documento concluye que la Comisión debe tratar de contrarrestar la disminución de la financiación en investigación sobre energías renovables y movilidad sostenible. También anuncia que el impulso a las energías renovables se complementará en los siguientes meses con la iniciativa sobre energía marina y la red energética transeuropea.

En relación a la reducción de las emisiones de efecto invernadero diferentes del CO2, concretamente sobre los gases fluorados, se aprobó la Decisión de Ejecución (UE) 2020/1604 de la Comisión, de 23 de octubre de 2020, por la que se determinan, de conformidad con el Reglamento (UE) n.o 517/2014 del Parlamento Europeo y del Consejo, sobre los gases fluorados de efecto invernadero, los valores de referencia para el período comprendido entre el 1 de enero de 2021 y el 31 de diciembre de 2023 de cada productor o importador que haya comercializado legalmente hidrofluorocarburos en el mercado de la Unión desde el 1 de enero de 2015, según lo notificado en virtud de dicho Reglamento [notificada con el número C(2020) 9500] (Texto pertinente a efectos del EEE).

En relación a las emisiones de otro gas de efecto invernadero diferente del $\mathrm{CO} 2$, las emisiones de metano, se publicó la Comunicación de la Comisión al Parlamento Europeo, al Consejo, al Comité Económico y Social Europeo y al Comité de las Regiones sobre la estrategia de la UE para reducir las emisiones de metano. Apunta que el metano es el gas de efecto invernadero que más se libera en la Unión después del $\mathrm{CO} 2$, con lo que es importante que se reduzcan sus emisiones y en concreto se calcula que debería ser de un mínimo del 37\% para 2030 comparado con las emisiones de 2005. Para esta reducción la estrategia propuesta en esta comunicación se basa en una combinación de medidas sectoriales e intersectoriales, que afectan 
especialmente a los sectores de la agricultura, los residuos y la energía, los principales generadores de metano.

Durante el período analizado en esta crónica se abrió una consulta pública sobre la propuesta de reglamento "Objetivos nacionales de reducción de emisiones (Reglamento de reparto del esfuerzo) - revisión basada en el Plan del Objetivo Climático para 2030", que estuvo abierta entre el 13 de noviembre de 2020 y el 5 de febrero de 2021. Pretende revisar el reglamento por el que se establecen las reducciones vinculantes de gases de emisiones de gases de efecto invernadero para cada Estado miembro de cara a la consecución de los objetivos climáticos para 2030. Hay que mencionar también aquí la aprobación del Dictamen del Comité Europeo de las Regiones - El impacto del cambio climático en las regiones: evaluación del Pacto Verde Europeo. El comité pone de manifiesto que la mayor parte de medidas para la mitigación y, especialmente, la adaptación al cambio climático las adoptan los entes locales y regionales. Recuerda que los entes locales y regionales son los que están mejor posicionados para hacer participar a la ciudadanía e incentivar su implicación en la lucha por el cambio climático, por lo que pide a la Comisión que integre la Agenda Urbana al Pacto Verde Europeo y que se incorpore a los entes locales y regionales de forma más determinante al despliegue de este pacto.

En el ámbito de la adaptación al cambio climático no se adoptaron normas de derecho positivo, pero si se emitió la Comunicación de la Comisión al Parlamento Europeo, al Consejo, al Comité Económico y Social Europeo y al Comité de las Regiones: Forjar una Europa resiliente al cambio climático - La nueva estrategia de adaptación al cambio climático de la UE. Este documento apunta que el cambio climático es una realidad muchos efectos del cual son inevitables a pesar de los esfuerzos que la Unión pueda hacer para frenarlo. Al mismo tiempo constata que la UE no está preparada para hacer frente a la creciente intensidad de las repercusiones del cambio climático, con lo que la estrategia en cuestión pretende reforzar su resiliencia de cara a 2050 en coordinación con todos los ámbitos que tienen mayor incidencia en este aspecto. Propone, entre otras cosas, mejorar el conocimiento sobre adaptación climática, incentivar una adaptación más sistémica a todos los niveles, incrementar la cooperación internacional en materia de adaptación. 
También sobre la cuestión de la adaptación se emitió el Dictamen del Comité Europeo de las Regiones - Oportunidades y sinergias de una adaptación preventiva al cambio climático para promover la sostenibilidad y la calidad de vida en las regiones y municipios: ¿qué condiciones marco se necesitan para ello?. Observa que hay una divergencia muy grande entre Estados miembros por lo que respecta a la adaptación climática a nivel local. En ese sentido pide que los entes locales y regionales puedan desempeñar un papel más relevante en las políticas de adaptación en, por ejemplo, la gestión de los fondos europeos para este objetivo o la participación en la generación de conocimiento mediante plataformas científicas locales.

En relación a la regulación de los derechos de emisión de gases de efecto invernadero encontramos varios instrumentos que obedecen a la repartición de estos derechos sin más trascendencia jurídica o política. Por una parte, encontramos las decisiones relativas a los actos de asignación de derechos de emisiones, ya sea sobre su determinación de los derechos totales disponibles o bien sobre la asignación y disponibilidad para su comercio para cada Estado:

- Decisión (UE) 2020/1722 de la Comisión de 16 de noviembre de 2020 relativa a la cantidad de derechos de emisión que deben expedirse para el conjunto de la Unión en 2021 de conformidad con el régimen de comercio de derechos de emisión de la UE [notificada con el número C(2020) 7704] (Texto pertinente a efectos del EEE).

- Decisión de Ejecución (UE) 2020/1834 de la Comisión de 3 de diciembre de 2020 relativa a las emisiones de gases de efecto invernadero contempladas en la Decisión n.o 406/2009/CE del Parlamento Europeo y del Consejo correspondientes a cada Estado miembro en 2018.

- Decisión de Ejecución (UE) 2020/2126 de la Comisión de 16 de diciembre de 2020 por la que se establecen las asignaciones anuales de emisiones de los Estados miembros para el período comprendido entre 2021 y 2030 de conformidad con el Reglamento (UE) 2018/842 del Parlamento Europeo y del Consejo (Texto pertinente a efectos del EEE).

- Decisión (UE) 2020/2166 de la Comisión de 17 de diciembre de 2020 relativa a la determinación de las cuotas sometidas a subasta de los Estados miembros durante el período 2021-2030 del régimen de comercio de derechos de emisión de la UE [notificada con el número C(2020) 8945] (Texto pertinente a efectos del EEE). 
- Decisión (UE) 2021/355 de la Comisión de 25 de febrero de 2021 relativa a las medidas nacionales de aplicación para la asignación gratuita transitoria de derechos de emisión de gases de efecto invernadero con arreglo al artículo 11, apartado 3, de la Directiva 2003/87/CE del Parlamento Europeo y del Consejo [notificada con el número C(2021) 1215] (Texto pertinente a efectos del EEE).

Por otra parte, encontramos las decisiones para introducir cambios en los cuadros nacionales de asignaciones:

- Decisión de la Comisión de 8 de octubre de 2020 por la que se da instrucciones al administrador central del Diario de Transacciones de la Unión Europea para que introduzca cambios en los cuadros nacionales de asignación de Alemania en el Diario de Transacciones de la Unión Europea 2020/C 349/06.

- Decisión de la Comisión, de 14 de octubre de 2020, por la que se dan instrucciones al administrador central del Diario de Transacciones de la Unión Europea para que introduzca cambios en los cuadros nacionales de asignación de Bélgica, Chequia, Dinamarca, Alemania, Francia, Letonia, Lituania, Polonia, Portugal, Rumanía y el Reino Unido en el Diario de Transacciones de la Unión Europea.

- Decisión de la Comisión de 16 de diciembre de 2020 por la que se dan instrucciones al administrador central para que anote en el Diario de Transacciones de la Unión Europea los cuadros nacionales de asignación para la aviación de Bélgica, Bulgaria, Chipre, Chequia, Dinamarca, Alemania, Estonia, Irlanda, Grecia, España, Francia, Croacia, Islandia, Italia, Letonia, Lituania, Luxemburgo, Hungría, Malta, Ios Países Bajos, Noruega, Austria, Polonia, Portugal, Rumanía, Eslovenia, Eslovaquia, Finlandia y Suecia 2021/C 47 I/01.

En relación al seguimiento y la notificación de las emisiones en el marco del régimen de comercio de derechos de emisión de gases de efecto invernadero se aprobó el Reglamento de Ejecución (UE) 2020/2085 de la Comisión de 14 de diciembre de 2020 por el que se modifica y corrige el Reglamento de Ejecución (UE) 2018/2066 sobre el seguimiento y la notificación de las emisiones de gases de efecto invernadero en aplicación de la Directiva 2003/87/CE del Parlamento Europeo y del Consejo (Texto pertinente a efectos del EEE).

También se han adoptado dos decisiones para determinar la posición que la Unión debe adoptar en el Comité Mixto con Suiza para la vinculación de sus regímenes de 
comercio de derechos de gases de efecto invernadero, que en ambos casos remite al proyecto de decisión ya elaborado por este mismo comité:

- Decisión (UE) 2020/1492 del Consejo de 12 de octubre de 2020 relativa a la posición que debe adoptarse en nombre de la Unión Europea en el Comité Mixto establecido por el Acuerdo entre la Unión Europea y la Confederación Suiza relativo a la vinculación de sus regímenes de comercio de derechos de emisión de gases de efecto invernadero en relación con la adopción de procedimientos operativos comunes (Texto pertinente a efectos del EEE).

- Decisión (UE) 2020/1493 del Consejo de 12 de octubre de 2020 relativa a la posición que debe adoptarse, en nombre de la Unión Europea, en el Comité Mixto establecido por el Acuerdo entre la Unión Europea y la Confederación Suiza relativo a la vinculación de sus regímenes de comercio de derechos de emisión de gases de efecto invernadero, por lo que respecta a la modificación de los anexos I y II del Acuerdo y la adopción de normas técnicas de enlace (Texto pertinente a efectos del EEE).

Aún sobre los derechos de emisión de gases de efecto invernadero se emitieron dos informes. El primero, el Informe de la Comisión al Parlamento Europeo y al Consejo: Informe sobre el funcionamiento del mercado europeo del carbono, responde a su elaboración anual obligatoria y cubre el año 2019. Destaca la reducción de más del 9\% de las emisiones respecto el 2018 debido principalmente a la penetración de las energías renovables en la producción de energía, notándose un crecimiento solo en el sector de la aviación. Es por eso que en la revisión del Régimen Comercio de Derechos de Emisiones de la UE previsto en el marco del Pacto Verde Europeo es probable que conlleve importantes cambios en relación a la aviación.

El segundo es el Informe de la Comisión al Parlamento Europeo y al Consejo: Análisis actualizado de los efectos climáticos de la aviación no relacionados con el CO2 y posibles medidas políticas con arreglo al artículo 30, apartado 4, de la Directiva sobre el comercio de derechos de emisión de la UE. Elaborado a petición de los dos colegisladores, el informe concluye que por tal de reducir los efectos climáticos de la aviación no relacionados con el $\mathrm{CO} 2$ se pueden adoptar medidas adicionales de dos tipos: medidas de tipo financiero tales como la imposición de gravámenes a las emisiones de NOx, o bien medidas respecte a la composición del combustible utilizado y la optimización del tránsito aéreo. 
Coincidiendo temáticamente con los informes justo antes mencionados, se han abierto a consulta pública dos iniciativas. La primera, "Cambio climático: actualización del régimen de comercio de derechos de emisión (RCDE) de la UE", es una propuesta de directiva que estuvo abierta del 13 de noviembre de 2020 al 5 de febrero de 2021 con el objetivo de revisar el Régimen Comercio de Derechos de Emisiones de la UE y ampliarlo a más sectores económicos.

La segunda iniciativa se titulaba "Régimen de comercio de derechos de emisión de la UE: normas actualizadas para la aviación" y estuvo abierta a consulta pública del 1 de octubre de 2020 al 14 de enero de 2021. Se trata de una propuesta de reglamento que también pretende modificar el Régimen Comercio de Derechos de Emisiones de la UE, pero con el objetivo más limitado de aplicar los objetivos climáticos para 2030 también a la aviación internacional y aumentar la cuota de derechos de emisiones subastados.

Por último, en relación a la protección de la capa de ozono, se aprobó la Decisión de Ejecución (UE) 2020/2181 de la Comisión de 17 de diciembre de 2020 por la que se determinan los límites cuantitativos y se asignan cuotas de sustancias reguladas en el marco del Reglamento (CE) n.o 1005/2009 del Parlamento Europeo y del Consejo, sobre sustancias que agotan la capa de ozono, para el período comprendido entre el 1 de enero y el 31 de diciembre de 2021 [notificada con el número C(2020) 8996] (Los textos en lenguas alemana, búlgara, checa, croata, española, francesa, griega, húngara, inglesa, italiana, letona, maltesa, neerlandesa, polaca y portuguesa son los únicos auténticos).

\subsection{Cuestiones transversales}

Durante el período de tiempo comprendido en esta crónica en el ámbito del acceso a la justicia medioambiental se publicó la Comunicación de la Comisión al Parlamento Europeo, al Consejo, al Comité Económico y Social Europeo y al Comité de las Regiones: Mejorar el acceso a la justicia en materia de medio ambiente en la UE y sus Estados miembros. Responde al compromiso de la Comisión de revisar el Reglamento de Aarhus en el marco del Pacto Verde Europeo con el fin de mejorar los procedimientos judiciales y administrativos para acceder a la justicia medioambiental para la ciudadanía y las ONGs. Las prioridades de actuación esbozadas en esta 
comunicación son, en primer lugar, asegurar la trasposición de la normativa sobre acceso a la justicia medioambiental por parte de los Estados miembros como tienen la obligación de hacer; en segundo lugar, la inclusión por parte de los colegisladores de provisiones relativas al acceso a la justicia en todas las normas de derecho derivado de materia medioambiental para mejorar la seguridad jurídica en este ámbito; en tercer lugar, incentivar la revisión de la normativa nacional diferente de la derivada del derecho europeo que pone obstáculos al acceso a la justicia medioambiental; y, por último, asegurar que los tribunales nacionales garantizan el derecho a un tutela judicial efectiva de acuerdo con el derecho de la Unión Europea.

También vinculado a la cuestión del acceso a la justicia medioambiental hay que mencionar el recurso de la Comisión Europea por incumplimiento de la normativa europea sobre hábitats y protección de las aves por parte un Estado miembro. Polonia fue llevada ante el Tribunal de Justicia de la Unión Europea por el incumplimiento de la Directiva de Hábitats y la Directiva de aves. Concretamente la Comisión denuncia que la ley polaca no prevé mecanismos suficientes para el acceso a la justicia en relación al incumplimiento de la obligación de realizar una evaluación de impacto de los planes de gestión forestal sobre la Red Natura 2000 antes de su autorización. El recurso responde a la falta de progreso respecto al compromiso en 2019 por parte de Polonia para reformar su normativa al respecto.

En relación a la financiación de las políticas ambientales hay que recordar que al finalizar el año 2020 también expiró el Marco Financiero Plurianual (MFP) 2014-2020, por lo que después de largas negociaciones se aprobó el Reglamento (UE, EURATOM) 2020/2093 del Consejo de 17 de diciembre de 2020 por el que se establece el marco financiero plurianual para el período 2021-2027. No es fácil valorar el cambio que supone en términos de financiación para las políticas ambientales de la Unión porque los techos de gasto se asignan con encabezados sensiblemente diferentes entre Marcos Financieros Plurianuales distintos. En este caso podemos observar una disminución si comparamos los 356,374 millones de euros del nuevo MFP bajo el encabezado "Recursos naturales y medioambiente" con los 373,870 del anterior bajo el encabezado "Crecimiento sostenible: Recursos naturales", pero haría falta un análisis más detallado para valorar los límites de gasto por diferentes categorías que se esconden en estos títulos generales, lo cual queda fuera del alcance de esta crónica. 
En el ámbito de las cuentas económicas europeas medioambientales se publicó el Informe de la Comisión al Parlamento europeo y al Consejo sobre el ejercicio de los poderes para adoptar actos delegados que otorga a la Comisión el Reglamento (UE) n.. 691/2011, relativo a las cuentas económicas europeas medioambientales. Concluye que la Comisión ha ejercido correctamente sus funciones de acuerdo con la delegación de poderes y pide seguir disponiendo de ellos en previsión de necesitar aprobar actos delegados en el futuro para mejorar y adaptar la información medioambiental a las nuevas necesidades que puedan surgir.

En el ámbito de la regulación de la auditoría ambiental sobre instalaciones industriales se aprobó la Decisión (UE) 2020/1802 de la Comisión de 27 de noviembre de 2020 por la que se modifica la Guía del usuario en la que figuran los pasos necesarios para participar en el EMAS con arreglo al Reglamento (CE) n.o 1221/2009 del Parlamento Europeo y del Consejo, relativo a la participación voluntaria de organizaciones en un sistema comunitario de gestión y auditoría medioambientales (EMAS) [notificada con el número C(2020) 8151] (Texto pertinente a efectos del EEE). En esta se amplía a las empresas de los sectores de la venta al por menor y la asistencia en establecimientos residenciales y servicios sociales sin alojamiento la opción de optar a la utilización del método de muestreo para la verificación como organizaciones con diferentes centros.

También se circunscribe en el período observado en esta crónica el Informe de la Comisión al Parlamento Europeo, al Consejo y al Comité Económico y Social Europeo: evaluando la aplicación de la Directiva 2013/30/UE del Parlamento Europeo y del Consejo, de 12 de junio de 2013, sobre la seguridad de las operaciones relativas al petróleo y al gas mar adentro, y que modifica la Directiva 2004/35/CE. El 2015 expiró el período de aplicación de la directiva para los Estados y el 2018 el período para las industrias, con lo que este informe pretende hacer un balance general del resultado de su aplicación. El informe detecta una aceptación favorable de las medidas introducidas por la directiva por parte de todas las partes interesadas, si bien algunas ONGs ambientales señalaron la necesidad de incrementar ciertas medidas de seguridad para prevenir accidentes y de reforzar los mecanismos de seguridad financiera en caso de accidente industrial. 


\section{OTRAS POLÍTICAS SECTORIALES DE LA UNIÓN QUE AFECTAN AL MEDIO AMBIENTE}

\subsection{Agricultura}

En el ámbito de la política agrícola encontramos un reglamento relevante para esta crónica, el Reglamento (UE) 2020/2220 del Parlamento Europeo y del Consejo de 23 de diciembre de 2020 por el que se establecen determinadas disposiciones transitorias para la ayuda del Fondo Europeo Agrícola de Desarrollo Rural (Feader) y del Fondo Europeo Agrícola de Garantía (FEAGA) en los años 2021 y 2022, y por el que se modifican los Reglamentos (UE) n.o 1305/2013, (UE) n.o 1306/2013 y (UE) n.o 1307/2013 en lo que respecta a sus recursos y a su aplicación en los años 2021 y 2022 y el Reglamento (UE) n.o 1308/2013 en lo que respecta a los recursos y la distribución de dicha ayuda en los años 2021 y 2022. La modificación del Reglamento $1305 / 2013$ es relevante desde el punto vista medioambiental porque permiten a los Estados miembros establecer para los compromisos que deban contraerse en 2021 y 2022 períodos superiores a los tres años en sus programas de desarrollo rural si los objetivos ambientales y climáticos lo justifican. También establece unas provisiones de recuperación de la situación generada por el Covid-19 a través del Feder para el sector agrícola y las zonas rurales que deberá cumplir criterios ambientales tales como la producción agrícola ecológica, criterios climáticos, de bienestar animal y de protección del suelo en un 37\% de su cuantía para los años 2021 y 2022.

También se emitió el Informe de la Comisión al Parlamento Europeo y al Consejo sobre la aplicación del Reglamento (UE) n.․ 1144/2014 del Parlamento Europeo y del Consejo sobre acciones de información y de promoción relativas a productos agrícolas en el mercado interior y en terceros países. Este documento hace una evaluación de la política de promoción del sector agrícola entre 2016 y 2020 . El resultado que es relevante destacar aquí son las incoherencias detectadas entre esta política y las políticas ambientales y climáticas de la Unión. En ese sentido la Comisión recomienda que en el próximo examen se valore de qué manera la política de promoción del sector agrícola puede contribuir a la transición hacia una agricultura más sostenible y adecuarse mejor a sus objetivos de acuerdo con las iniciativas que forman el Pacto Verde Europeo. 
En relación al ámbito agrícola también hay que hacer referencia a dos dictámenes del Comité Europeo de las Regiones. El Dictamen del Comité Europeo de las Regiones - Del productor al consumidor (de la granja a la mesa): la dimensión local y regional acoge muy favorablemente la Estrategia "Del productor al consumidor" pero también hace diversas críticas y propuestas, de lo que cabe destacar: la petición de que se tengan más en cuenta las cadenas de suministro cortas; la recomendación de que se flexibilicen los criterios de contratación pública para favorecer los productos de proximidad, como sería el caso de los comedores escolares; la recomendación de que se tengan en cuenta las políticas territoriales locales para la aplicación de modos de producción agrícola biológica; y el uso más sostenible de los recursos naturales en la agricultura.

También se emitió el Dictamen del Comité Europeo de las Regiones - Agroecología. El Comité subraya que la agroecología encaja de forma natural con otras políticas que la Unión ha adoptado de cara a 2030 como la Estrategia "Del productor a la mesa" o la Estrategia sobre biodiversidad de la UE. También afirma que una agricultura ecológica y basada en los productos locales es una buena forma de recuperación para los territorios en el contexto de la Covid-19, así como de fortalecer la cohesión entre zonas rurales y las ciudades. En ese sentido solicita que la Comisión apoye el desarrollo de circuitos cortos mediante proyectos locales, los entes locales y regionales en la implementación de la agroecología y otras medidas tales como la reducción del IVA para productos ecológicos, locales y de temporada.

En lo que atañe a la normativa forestal solo se ha aprobado el Reglamento Delegado (UE) 2021/268 de la Comisión de 28 de octubre de 2020 por el que se modifica el anexo IV del Reglamento (UE) 2018/841 del Parlamento Europeo y del Consejo en lo que respecta a los niveles de referencia forestal que deberán aplicar los Estados miembros para el período comprendido entre 2021 y 2025 (Texto pertinente a efectos del EEE).

Asimismo se emitió el Informe de la Comisión al Parlamento Europeo y al Consejo Reglamento (UE) n.o 995/2010 del Parlamento Europeo y del Consejo, de 20 de octubre de 2010, por el que se establecen las obligaciones de los agentes que comercializan madera y productos de la madera (el Reglamento de la UE sobre la madera): Informe bienal para el período de marzo de 2017 a febrero de 2019. Este es el tercer informe de la Comisión sobre la aplicación del Reglamento 995/2010, que 
entre otras cosas prohíbe la comercialización de madera obtenida de forma ilegal en la Unión. Concluye que en conjunto se han reducido las sanciones por incumplimiento del reglamento, pero señala que su aplicación es muy desigual entre Estados miembros cosa que puede perjudicar su eficacia. En ese sentido reclama que se aumente la capacidad técnica y los recursos por tal de realizar los controles necesarios.

Es pertinente comentar aquí la iniciativa de reglamento "Uso de la tierra, cambio de uso de la tierra y silvicultura - revisión de las normas de la UE", que estuvo abierta a consulta pública del 13 de noviembre de 2020 al 5 de febrero de 2021. Tiene por objeto revisar la normativa relativa al uso de la tierra y a la práctica de la silvicultura para la reducción de emisiones de efecto invernadero con el fin de alcanzar los objetivos para 2050 de ser un continente climáticamente neutro.

\subsection{Pesca}

En el sector pesquero se aprobó un reglamento concerniente a la regulación general de las pesquerías. Se trata del Reglamento (UE) 2021/56 del Parlamento Europeo y del Consejo de 20 de enero de 2021 por el que se establecen las medidas de ordenación, conservación y control aplicables en la zona de la Convención Interamericana del Atún Tropical y por el que se modifica el Reglamento (CE) n.o $520 / 2007$ del Consejo. Establece el régimen general en cuanto a los períodos de veda de acuerdo a los tipos de pesca permitidos, el uso de técnicas de pesca, medidas de seguridad y requisitos aplicables a los buques pesqueros. También fija las medidas de protección de las especies marinas y otras especies, como diferentes tipos de tiburones, rajiformes, aves marinas, tortugas o delfines, así como la prohibición de ciertas técnicas de pesca que pueden ser peligrosas para las especies marinas y las obligaciones de informar sobre el avistamiento ciertos animales.

En relación a este último punto, se abrió a consulta pública entre el 27 de noviembre de 2020 y el 19 de febrero de 2021 la propuesta de acto "Observación de los océanos: responsabilidad compartida". Tiene por objetivo establecer una planificación y colaboración conjunta europea de las actividades de observación que permita obtener datos unificados que sirvan de base para la aplicación del Pacto Verde Europeo en el ámbito marítimo. 
También se abrió a consulta pública otra iniciativa del ámbito pesquero. La propuesta de reglamento "Pescado y marisco: revisión de las normas de comercialización" estuvo abierta a consulta pública entre el 17 de noviembre de 2020 y el 23 de febrero de 2021 y pretende actualizar las normas de comercialización del pescado y el marisco para garantizar, entre otras cosa, la sostenibilidad de las capturas.

Se aprobó el Reglamento de Ejecución (UE) 2021/141 de la Comisión de 5 de febrero de 2021 por el que se amplía una excepción al Reglamento (CE) n.o 1967/2006 del Consejo en lo relativo a la prohibición de faenar por encima de hábitats protegidos, la distancia mínima de la costa y la profundidad marina mínima para los arrastreros que pescan con «gangui» en determinadas aguas territoriales de Francia (ProvenzaAlpes-Costa Azul). Con este reglamento se amplía la excepción a la prohibición en cuestión, que caducó el 3 de diciembre de 2020. Según los datos aportados por Francia sobre las capturas en esta región marítima, el tipo de pesca practicado y las características de la plataforma continental de esta pesquería la Comisión valoró admisible la ampliación de la excepción hasta el 11 de mayo de 2022.

Respecto a la lucha contra la pesca ilegal y no reglamentada se aprobaron las siguientes decisiones:

- Decisión (UE) 2020/1582 del Consejo de 23 de octubre de 2020 relativa a la posición que debe adoptarse, en nombre de la Unión Europea, en las reuniones de las Partes en el Acuerdo para impedir la pesca no reglamentada en alta mar en el Océano Ártico central.

- Decisión (UE) 2021/351 del Consejo de 22 de febrero de 2021 relativa a la posición que debe adoptarse en nombre de la Unión Europea en las reuniones de las Partes en el Acuerdo sobre medidas del Estado rector del puerto destinadas a prevenir, desalentar y eliminar la pesca ilegal, no declarada y no reglamentada.

Estas se remiten a los documentos del Consejo ST 11439/20 y ST 5410/21, que establecen unos principios y directrices generales sobre la posición que debe adoptar la Unión en la reunión de las partes de este tratado.

Asimismo, también se adoptó la Decisión de la Comisión de 17 de febrero de 2021 por la que se cursa una notificación a la República de Camerún sobre la posibilidad de ser considerada tercer país no cooperante en la lucha contra la pesca ilegal, no declarada y no reglamentada [notificada con el número C(2021) 981] 2021/C 59 I/01. 
Posteriormente deberá establecerse un plazo para que Camerún pueda hacer sus alegaciones a la notificación y corregir la situación antes de que sea considerado tercer país no cooperante en la lucha contra la pesca ilegal.

Sobre esta misma cuestión se publicó el Informe de la Comisión al Parlamento Europeo y al Consejo sobre la aplicación del Reglamento (CE) n.․ 1005/2008 del Consejo, por el que se establece un sistema comunitario para prevenir, desalentar y eliminar la pesca ilegal, no declarada y no reglamentada (INDNR) (el Reglamento INDNR). A partir principalmente de la información proporcionada por los Estados miembros, la Comisión hace un balance positivo de la aplicación del reglamento en cuestión. Considera que la clave del buen resultado radica en que no pretende imponer la normativa de la Unión a terceros países, sino simplemente vigilar por el cumplimiento de las obligaciones internacionales contraídas como Estados de abanderamiento, Estados rectores del puerto, Estados ribereños o Estados de comercialización.

Sobre la protección de poblaciones de peces, se aprobaron dos decisiones para la adopción de la posición de la Unión en organizaciones internacionales para este fin, la primera de ellas como consecuencia de la retirada de Reino Unido de la Unión:

- Decisión (UE) 2020/1517 del Consejo de 19 de octubre de 2020 relativa a la posición que debe adoptarse, en nombre de la Unión Europea, en el Consejo de la Organización para la Conservación del Salmón del Atlántico Norte creado por el Convenio para la conservación del salmón en el Atlántico Norte por lo que respecta a la solicitud de adhesión del Reino Unido a dicho Convenio, y por la que se deroga la Decisión (UE) 2019/937

- Decisión (UE) 2020/1580 del Consejo de 23 de octubre de 2020 por la que se modifica la Decisión (UE) 2020/721 para incluir la posición que debe adoptarse en nombre de la Unión Europea en el Comité de Protección del Medio Marino de la Organización Marítima Internacional en su 75.o período de sesiones y en el Comité de Seguridad Marítima de la Organización Marítima Internacional en su 102.o período de sesiones, en lo relativo a la aprobación de una circular MSC-MEPC.5 sobre el modelo de acuerdo para autorizar a organizaciones reconocidas que actúen en nombre de la administración 
Durante el período observado en esta crónica se aprobaron veintiún reglamentos para el cierre de pesquerías de determinadas zonas y para determinados Estados miembros. De forma meramente enumerativa:

- Reglamento (UE) 2020/1476 de la Comisión de 10 de octubre de 2020 por el que se establece el cierre de las pesquerías de atún blanco del norte en el océano Atlántico, al norte del paralelo $5^{\circ} \mathrm{N}$, para los buques que enarbolan pabellón de Irlanda

- Reglamento (UE) 2020/1518 de la Comisión de 15 de octubre de 2020 por el que se establece el cierre de las pesquerías de lenguado europeo en las zonas $7 \mathrm{~h}, 7 \mathrm{j}$ y $7 \mathrm{k}$ para los buques que enarbolan pabellón de Bélgica

- Reglamento (UE) 2020/1519 de la Comisión de 15 de octubre de 2020 por el que se establece el cierre de las pesquerías de solla en las zonas $7 \mathrm{~h}, 7 \mathrm{j}$ y $7 \mathrm{k}$ para los buques que enarbolan pabellón de Bélgica

- Reglamento (UE) 2020/1520 de la Comisión de 15 de octubre de 2020 por el que se establece el cierre de las pesquerías de solla en las zonas $7 \mathrm{~h}, 7 \mathrm{j}$ y $7 \mathrm{k}$ para los buques que enarbolan pabellón de Francia

- Reglamento (UE) 2020/1521 de la Comisión de 15 de octubre de 2020 por el que se establece el cierre de las pesquerías de abadejo en las zonas $8 \mathrm{a}, 8 \mathrm{~b}, 8 \mathrm{~d}$ y 8 e para los buques que enarbolan pabellón de Bélgica

- Reglamento (UE) 2020/1522 de la Comisión de 15 de octubre de 2020 por el que se establece el cierre de las pesquerías de merluza en las zonas $8 \mathrm{a}, 8 \mathrm{~b}, 8 \mathrm{~d}$ y $8 \mathrm{e}$ para los buques que enarbolen pabellón de Bélgica

- Reglamento (UE) 2020/1523 de la Comisión de 15 de octubre de 2020 por el que se establece el cierre de las pesquerías de lenguado europeo en las zonas $8 \mathrm{a}$ y $8 \mathrm{~b}$ para los buques que enarbolan pabellón de Bélgica

- Reglamento (UE) 2020/1557 de la Comisión de 21 de octubre de 2020 por el que se establece el cierre de las pesquerías de merlán en la zona 8 para los buques que enarbolen pabellón de Bélgica

- Reglamento (UE) 2020/1558 de la Comisión de 21 de octubre de 2020 por el que se establece el cierre de las pesquerías de rayas, pastinacas y mantas de aguas de la Unión de las zonas 8 y 9 para los buques que enarbolen pabellón de Bélgica 
- Reglamento (UE) 2020/1626 de la Comisión de 27 de octubre de 2020 por el que se cierran las pesquerías de alfonsinos en aguas de la Unión y aguas internacionales de las zonas $3,4,5,6,7,8,9,10,12$ y 14, para los buques que enarbolen pabellón de Portugal

- Reglamento (UE) 2020/1660 de la Comisión de 15 de octubre de 2020 por el que se establece el cierre de las pesquerías de gallos en las zonas $8 \mathrm{a}, 8 \mathrm{~b}, 8 \mathrm{~d}$ y $8 \mathrm{e}$ para los buques que enarbolan pabellón de Bélgica

- Reglamento (UE) 2020/1750 de la Comisión de 15 de octubre de 2020 por el que se establece el cierre de las pesquerías de rape en las zonas $8 \mathrm{a}, 8 \mathrm{~b}, 8 \mathrm{~d}$ y $8 \mathrm{e}$ para los buques que enarbolan pabellón de Bélgica

- Reglamento (UE) 2020/1754 de la Comisión de 19 de noviembre de 2020 por el que se establece el cierre de las pesquerías de patudo en el océano Atlántico por parte de los buques que enarbolen pabellón de Portugal

- Reglamento (UE) 2020/1781 del Parlamento Europeo y del Consejo de 25 de noviembre de 2020 por el que se modifica el Reglamento (UE) 2016/1139 en lo que respecta a la reducción de la capacidad de pesca en el mar Báltico, y el Reglamento (UE) n.o 508/2014 en lo que respecta a la paralización definitiva de la actividad pesquera de las flotas que pescan bacalao del Báltico oriental, bacalao del Báltico occidental y arenque del Báltico occidental

- Reglamento (UE) 2021/71 de la Comisión de 21 de enero de 2021 por el que se cierran las pesquerías de alfonsinos en aguas de la Unión y aguas internacionales de las zonas 3, 4, 5, 6, 7, 8, 9, 10, 12 y 14 para los buques que enarbolen pabellón de Francia

- Reglamento (UE) 2021/72 de la Comisión de 22 de enero de 2021 por el que se establece el cierre de las pesquerías de raya mosaico en aguas de la Unión de las zonas $7 \mathrm{~d}$ y $7 \mathrm{e}$ para los buques que enarbolen pabellón de Francia

- Reglamento (UE) 2021/93 de la Comisión de 25 de enero de 2021 por el que se establece el cierre de las pesquerías de arenque en aguas de la Unión, de las Islas Feroe y de Noruega y aguas internacionales de las zonas 1 y 2 para los buques que enarbolen pabellón 
- Reglamento (UE) 2021/375 de la Comisión de 24 de febrero de 2021 por el que se establece el cierre de las pesquerías de bacalao en la subzona 1 y la división $2 \mathrm{~b}$ para los buques que enarbolan el pabellón de determinados Estados miembros

- Reglamento (UE) 2021/376 de la Comisión de 24 de febrero de 2021 por el que se establece el cierre temporal de las pesquerías de gallinetas en la zona NAFO 3M para los buques que enarbolan el pabellón de un Estado miembro de la Unión Europea

- Reglamento (UE) 2020/1405 de la Comisión de 1 de octubre de 2020 por el que se cierran las pesquerías de gallineta nórdica en aguas de la Unión y aguas internacionales de la zona 5, así como en aguas internacionales de las zonas 12 y 14 , para los buques que enarbolen pabellón de España

- Reglamento (UE) 2020/1417 de la Comisión de 2 de octubre de 2020 por el que se establece el cierre de las pesquerías de mendo en la zona NAFO 3NO para los buques que enarbolan pabellón de un Estado miembro de la Unión Europea

Otra cuestión que acostumbra a generar un buen número de reglamentos, es el establecimiento de posibilidades de pesca por tipos de pez y por región marítima:

- Reglamento (UE) 2020/1485 del Consejo de 12 de octubre de 2020 que modifica el Reglamento (UE) 2019/2236 por el que se fijan, para 2020, las posibilidades de pesca aplicables a determinadas poblaciones y grupos de poblaciones de peces en el mar Mediterráneo y en el mar Negro

- Reglamento (UE) 2020/1579 del Consejo de 29 de octubre de 2020 por el que se establecen, para 2021, las posibilidades de pesca de determinadas poblaciones y grupos de poblaciones de peces en el mar Báltico y por el que se modifica el Reglamento (UE) 2020/123 en lo que respecta a determinadas posibilidades de pesca en otras aguas

- Reglamento (UE) 2020/2132 del Consejo de 17 de diciembre de 2020 por el que se modifica el Reglamento (UE) 2020/123 en lo que respecta a las posibilidades de pesca de faneca noruega en 2020

- Reglamento (UE) 2020/2227 del Parlamento Europeo y del Consejo de 23 de diciembre de 2020 por el que se modifica el Reglamento (UE) 2017/2403 en lo que se refiere a las autorizaciones de pesca para los buques pesqueros de la Unión en aguas 
del Reino Unido y las operaciones de pesca de los buques pesqueros del Reino Unido en aguas de la Unión.

- Reglamento (UE) 2021/90 del Consejo de 28 de enero de 2021 por el que se fijan, para 2021, las posibilidades de pesca aplicables a determinadas poblaciones y grupos de poblaciones de peces en el mar Mediterráneo y el mar Negro

- Reglamento (UE) 2021/91 del Consejo de 28 de enero de 2021 por el que se fijan para los buques pesqueros de la Unión las posibilidades de pesca en los años 2021 y 2022 de determinadas poblaciones de peces de aguas profundas

- Reglamento (UE) 2021/92 del Consejo de 28 de enero de 2021 por el que se establecen para 2021 las posibilidades de pesca para determinadas poblaciones y grupos de poblaciones de peces, aplicables en aguas de la Unión y, en el caso de los buques pesqueros de la Unión, en determinadas aguas no pertenecientes a la Unión

- Reglamento de Ejecución (UE) 2021/252 de la Comisión de 29 de enero de 2021 por el que se efectúa una deducción de la cuota de pesca asignada a Portugal para el boquerón debido a la sobrepesca practicada el año anterior

También en relación a la asignación de posibilidades de pesca, encontramos varios actos dirigidos a la celebración o renovación de acuerdos internacionales con terceros países a tal efecto. Concretamente se trata de los acuerdos con Mauritania, las Islas Cook, la República de Seychelles y la República de Senegal:

- Decisión (UE) 2020/1704 del Consejo de 23 de octubre de 2020 relativa a la firma, en nombre de la Unión, y a la aplicación provisional del Acuerdo en forma de Canje de Notas entre la Unión Europea y la República Islámica de Mauritania relativo a la prórroga del Protocolo por el que se fijan las posibilidades de pesca y la contrapartida financiera previstas en el Acuerdo de Asociación en el sector pesquero entre la Comunidad Europea y la República Islámica de Mauritania, Protocolo que expira el 15 de noviembre de 2020.

- Decisión (UE) 2021/99 del Consejo de 25 de enero de 2021 relativa a la celebración del Acuerdo en forma de Canje de Notas entre la Unión Europea y la República Islámica de Mauritania, relativo a la prórroga del Protocolo por el que se fijan las posibilidades de pesca y la contrapartida financiera previstas en el Acuerdo de Asociación en el sector pesquero entre la Comunidad Europea y la República Islámica de Mauritania, Protocolo que expira el 15 de noviembre de 2020. 
- Acuerdo en forma de Canje de Notas entre la Unión Europea y la República Islámica de Mauritania relativo a la prórroga del Protocolo por el que se fijan las posibilidades de pesca y la contrapartida financiera previstas en el Acuerdo de Asociación en el sector pesquero entre la Comunidad Europea y la República Islámica de Mauritania, protocolo que expira el 15 de noviembre de 2020.

- Acuerdo en forma de Canje de Notas entre la Unión Europea y el Gobierno de las Islas Cook relativo a la prórroga del protocolo de aplicación del Acuerdo de Colaboración de pesca sostenible entre la Unión Europea y el Gobierno de las Islas Cook.

- Decisión (UE) 2020/1545 del Consejo de 19 de octubre de 2020 relativa a la firma, en nombre de la Unión, y a la aplicación provisional del Acuerdo en forma de Canje de Notas entre la Unión Europea y el Gobierno de las Islas Cook relativo a la prórroga del Protocolo de aplicación del Acuerdo de Colaboración de pesca sostenible entre la Unión Europea y el Gobierno de las Islas Cook.

- Decisión (UE) 2021/113 del Consejo de 25 de enero de 2021 relativa a la celebración del Acuerdo en forma de Canje de Notas entre la Unión Europea y el Gobierno de las Islas Cook relativo a la prórroga del Protocolo de aplicación del Acuerdo de Colaboración de pesca sostenible entre la Unión Europea y el Gobierno de las Islas Cook.

- Decisión (UE) 2020/2000 del Consejo de 27 de noviembre de 2020 relativa a la celebración, en nombre de la Unión Europea, del Acuerdo de Colaboración de Pesca Sostenible entre la Unión Europea y la República de Seychelles y su Protocolo de aplicación (2020-2026).

- Decisión (UE) 2020/1786 del Consejo de 27 de noviembre de 2020 relativa a la celebración del Protocolo de aplicación del Acuerdo de colaboración de pesca sostenible entre la Unión Europea y la República de Senegal.

\subsection{Energía}

En el ámbito de las energías renovables se ha aprobado la Decisión de Ejecución (UE) 2021/359 del Consejo de 22 de febrero de 2021 por la que se autoriza a los Países Bajos a aplicar un tipo impositivo reducido a la electricidad suministrada a 
estaciones de recarga para vehículos eléctricos. Permite a los Países Bajos seguir aplicando el tipo impositivo reducido hasta el 1 de enero de 2025.

También se publicó la Comunicación de la Comisión al parlamento Europeo, al Consejo, al Comité Económico y Social Europeo y al Comité de las Regiones: Una estrategia de la UE para aprovechar el potencial de la energía renovable marina para un futuro climáticamente neutro. El documento pone de manifiesto el enorme potencial que representan las energías renovables marinas como los parques eólicos marinos, los parques fotovoltaicos flotantes o la energía mareomotriz debido al desarrollo tecnológico que se ha dado en este sector en los últimos años. No obstante, señala que para que ese desarrollo sea posible la Unión y los gobiernos nacionales deberían adaptar las políticas para que sea posible aumentar suficientemente la capacidad de instalación necesaria, y es en es en ese sentido que la Comisión presenta su estrategia.

Hay que hacer referencia a tres informes relevantes para esta sección que se han emitido durante el período analizado. El primero es el Informe de la Comisión al Parlamento Europeo, al Consejo, al Comité Económico y Social Europeo y al Comité de las Regiones: Informe de situación en materia de energía renovable. Afirma que en 2020 se cumplieron los objetivos en cuanto al porcentaje de energía proveniente de fuentes renovables al estimarse por encima del $22 \%$ y que el mercado es cada vez más autónomo en cuanto a las inversiones en energías renovables debido al progresivo abaratamiento de estas tecnologías. En cuanto a la energía renovable utilizada en el transporte solo 16 Estados miembros están en disposición de alcanzar el mínimo legal establecido en el 10\%.

El Informe de la Comisión al Parlamento Europeo y al Consejo sobre la situación de la competitividad de las energías limpias, pone de relieve que el sector de las energías limpias está generando más valor añadido que las energías tradicionales así como más empleos, al mismo tiempo que está creciendo como sector económico. No obstante, avisa que la reducción de la inversión en l+i puede frenar esta evolución positiva y anuncia que la Comisión propondrá a los Estados miembros que establezcan mínimos nacionales para la investigación en energías limpias. También señala que la menor dependencia de las energías fósiles reduce la dependencia de la importación de energía, que en todo caso se desplaza a las materias necesarias para el desarrollo de instalaciones de energía limpia. 
Por último, se publicó el Informe de la Comisión al Parlamento Europeo, al Consejo, al Comité Económico y Social Europeo y al Comité de las Regiones: Precios y costes de la energía en Europa. Pone de relieve que en 2019 y en 2020 se ha producido una reducción del precio de las energías renovables debido en gran parte al crecimiento de la producción de energía renovable y la reducción del coste de la tecnología necesaria para su producción. También remarca que esta disminución del precio de la energía ha sido desigual entre Estados miembros, cosa que sugiere la conveniencia de una mayor interconexión energética.

En el ámbito de la promoción de la eficiencia energética se han aprobado dos actos estrechamente vinculados relativos a la eficiencia de los edificios. En primer lugar se adoptó el Reglamento Delegado (UE) 2020/2155 de la Comisión de 14 de octubre de 2020 por el que se completa la Directiva 2010/31/UE del Parlamento Europeo y del Consejo mediante el establecimiento de un régimen común voluntario de la Unión Europea para la valoración del grado de preparación para aplicaciones inteligentes de los edificios (Texto pertinente a efectos del EEE). La función principal de este reglamento delegado es establecer un indicador de preparación para aplicaciones inteligentes de un edificio o de una unidad de un edificio, así como fijar una metodología común para su cálculo además de otras provisiones relativas al control y certificación.

En segundo lugar se aprobó el Reglamento de Ejecución (UE) 2020/2156 de la Comisión de 14 de octubre de 2020 por el que se detallan las modalidades técnicas para la aplicación efectiva de un régimen común voluntario de la Unión para la valoración del grado de preparación para aplicaciones inteligentes de los edificios (Texto pertinente a efectos del EEE). Este detalla las modalidades técnicas para la aplicación efectiva de un régimen común voluntario de la Unión para la valoración del grado de preparación para aplicaciones inteligentes de los edificios establecido en el reglamento delegado expuesto antes.

En relación con esta misma temática se publicaron un informe y una comunicación de forma conjunta sobre la eficiencia energética de los edificios. El informe enfatiza que el parque inmobiliario de Europa es antiguo y poco eficiente energéticamente a la vez que consumen alrededor del $40 \%$ de la energía de la Unión y producen el $32 \%$ de las emisiones de gases de efecto invernadero. La comunicación por su lado propone una estrategia muy ambiciosa de cara 2030 para una renovación masiva de los edificios 
por tal de mejorar su eficiencia energética con criterios de reducción de la pobreza energética, sostenibilidad y diseño ecológico. Las medidas incluyen la revisión de la normativa comunitaria sobre eficiencia energética, energías renovables y el régimen de comercio de derechos de emisiones:

- Comunicación de la Comisión al Parlamento Europeo, al Consejo, al Comité Económico y Social Europeo y al Comité de las Regiones: Oleada de renovación para Europa: ecologizar nuestros edificios, crear empleo y mejorar vidas.

- Informe de la Comisión al parlamento Europeo y al Consejo: Evaluación de 2020 sobre los progresos realizados por los Estados miembros en la aplicación de la Directiva 2012/27/UE relativa a la eficiencia energética, así como en el despliegue de edificios de consumo de energía casi nulo y de niveles óptimos de rentabilidad de los requisitos mínimos de eficiencia energética en la UE de conformidad con la Directiva 2010/31/UE, relativa a la eficiencia energética de los edificios.

Por último en este apartado hay que hacer referencia a la aprobación de un reglamento delegado sobre etiquetado energético, que por su carácter meramente técnico nos limitamos a nombrar: Reglamento Delegado (UE) 2021/340 de la Comisión de 17 de diciembre de 2020 por el que se modifican los Reglamentos Delegados (UE) 2019/2013, (UE) 2019/2014, (UE) 2019/2015, (UE) 2019/2016, (UE) 2019/2017 y (UE) 2019/2018 en lo relativo a los requisitos de etiquetado energético de las pantallas electrónicas, las lavadoras domésticas y las lavadoras-secadoras domésticas, las fuentes luminosas, los aparatos de refrigeración, los lavavajillas domésticos y los aparatos de refrigeración con función de venta directa (Texto pertinente a efectos del EEE).

\subsection{Transporte}

En relación al transporte ferroviario hay que destacar en primer lugar la Decisión (UE) 2020/2228 del Parlamento Europeo y del Consejo de 23 de diciembre de 2020 relativa al Año Europeo del Ferrocarril (2021). Con esta decisión se declaró el 2021 año del ferrocarril con el objetivo de fomentar su uso y apoyar a todos los niveles políticos y administrativos de la Unión a incrementar la cuota del ferrocarril en el transporte de pasajeros y mercancías entendiendo que, entre otras cosas, contribuye al objetivo de neutralidad climática para 2050. Entre las actividades propuestas para tal fin se 
encuentran las acciones de promoción de la imagen del ferrocarril, el fomento del transporte ferroviario para fines profesionales, intercambio de experiencias y buenas prácticas entre autoridades ferroviarias nacionales o el desarrollo de un sello para productos transportados por tren.

También sobre la cuestión del transporte ferroviario se publicó el Informe de la Comisión al Parlamento Europeo y al Consejo: Séptimo informe de seguimiento de la evolución del mercado ferroviario de conformidad con el artículo 15, apartado 4, de la Directiva 2012/34/UE del Parlamento Europeo y del Consejo. Constata que en 2018 el transporte ferroviario creció en conjunto, se amplió la red ferroviaria y siguió disminuyendo sus emisiones de gases de efecto invernadero. Aun así considera que hace falta seguir potenciando este sector de transporte con diferentes medidas: incrementar la competitividad en el mercado para mejorar el servicio ferroviario, mejorar el servicio ferroviario transfronterizo, mejorar el rendimiento de la infraestructura ferroviaria y reforzar la orientación al cliente.

En relación al transporte sostenible se publicó la Comunicación de la Comisión al Parlamento Europeo, al Consejo, al Comité Económico y Social Europeo y al Comité de las Regiones: Estrategia de movilidad sostenible e inteligente: encauzar el transporte europeo de cara al futuro. El documento expone primero la visión de la Comisión sobre el transporte, caracterizada por la ecologización, digitalización y la multimodalidad. Defiende que hace falta un cambio radical en este sentido y que con el nivel suficiente de ambición es posible alcanzar la reducción del $90 \%$ de las emisiones de gases de efecto invernadero de cara a 2050. Entre las iniciativas que propone destacan la creación de puertos y aeropuertos sin emisiones, la movilidad urbana caracterizada por el uso del transporte público intermodal y la bicicleta, el tránsito del transporte de mercancías de la carretera al ferrocarril en un $75 \%$, la tarificación del carbono. El documento incluye un plan de acción anexo a aplicar en los próximos cuatro años.

En relación a la normativa que afecta a las emisiones de gases de efecto invernadero por parte de vehículos se han aprobado los siguientes actos de carácter meramente técnico:

- Decisión de Ejecución (UE) 2020/1714 de la Comisión de 16 de noviembre de 2020 por la que se modifica la Decisión de Ejecución (UE) 2019/1119, en lo concerniente a 
la metodología de ensayo para determinados turismos eléctricos híbridos sin carga exterior y a fin de tener en cuenta el uso de combustibles alternativos, y la Decisión de Ejecución (UE) 2020/1339, en lo concerniente a las luces de posición traseras (Texto pertinente a efectos del EEE)

- Decisión de Ejecución (UE) 2020/1806 de la Comisión de 25 de noviembre de 2020 relativa a la aprobación de la utilización de la función de conducción a vela con el motor en marcha en turismos con motores de combustión interna y en turismos eléctricos híbridos sin carga exterior como tecnología innovadora, de conformidad con el Reglamento (UE) 2019/631 del Parlamento Europeo y del Consejo y por la que se derogan las Decisiones de Ejecución [...] de la Comisión (Texto pertinente a efectos del EEE)

- Reglamento Delegado (UE) 2020/2173 de la Comisión de 16 de octubre de 2020 por el que se modifican los anexos I, II y III del Reglamento (UE) 2019/631 del Parlamento Europeo y del Consejo a fin de actualizar los parámetros de seguimiento y aclarar determinados aspectos relativos al cambio del procedimiento de ensayo reglamentario (Texto pertinente a efectos del EEE)

- Decisión de Ejecución (UE) 2021/136 de la Comisión de 4 de febrero de 2021 por la que se corrigen la Decisión de Ejecución (UE) 2019/1119, relativa a la aprobación de una tecnología de iluminación eficiente para el exterior de los vehículos que utiliza diodos emisores de luz para su uso en vehículos de motor de combustión interna y en vehículos eléctricos híbridos no recargables desde el exterior como tecnología innovadora para la reducción de las emisiones de $\mathrm{CO} 2$ de los turismos de conformidad con el Reglamento (CE) n.o 443/2009 del Parlamento Europeo y del Consejo, y la Decisión de Ejecución (UE) 2020/1339, relativa a la aprobación, con arreglo al Reglamento (UE) 2019/631 del Parlamento Europeo y del Consejo, de una tecnología de iluminación eficiente para el exterior de los vehículos que utiliza diodos emisores de luz como tecnología innovadora para reducir las emisiones de $\mathrm{CO} 2$ de determinados vehículos comerciales ligeros en relación con el procedimiento de ensayo de vehículos ligeros armonizado a nivel mundial (Texto pertinente a efectos del EEE)

Aún en relación al transporte por carretera debemos incluir la publicación anual del Informe de la Comisión al Parlamento Europeo y al Consejo: Calidad de la gasolina y 
el gasóleo utilizados en el transporte por carretera en la Unión Europea (Año de referencia 2018). Este documento resume la información aportada por los Estados miembros, según la cual por lo general los límites de calidad se cumplen satisfactoriamente.

Sobre esta cuestión se abrió a consulta pública entre el 13 de noviembre de 2020 y el 5 de febrero de 2021 la propuesta de reglamento "Emisiones de CO2 de turismos y furgonetas - revisión de las normas de comportamiento". La iniciativa en cuestión pretende iniciar una revisión de la normativa sobre transporte en carretera de acuerdo con los objetivos fijados en el Pacto Verde Europeo para que de cara a 2025 se disponga de una vía clara para un transporte por carretera de cero emisiones.

\subsection{Acción exterior}

En el ámbito de la acción exterior vale la pena hacer referencia a tres comunicaciones relevantes para esta crónica ya que, a pesar de su carácter meramente político, integran cuestiones ambientales que podrían configurar el acercamiento de la Unión a ciertos retos globales. En primer lugar se publicó la Comunicación conjunta al parlamento Europeo, al Consejo Europeo y al Consejo: Una nueva agenda UE-EE. UU. para el cambio global. El documento empieza por resaltar el poder a nivel global que los esfuerzos de la Unión Europea junto los de Estados unidos representan de forma combinada, así como en poner de manifiesto la imperiosa necesidad de seguir cooperando para hacer frente a los problemas internacionales actuales. En ese sentido, el segundo ámbito en el que se pregona la necesidad de reforzar la cooperación es en la lucha contra el cambio climático y la pérdida de biodiversidad, por lo que propone trabajar de forma conjunta en todos los espacios multilaterales compartidos, tales como la OMC o el Convenio sobre Diversidad Biológica.

En segundo lugar se publicó la Comunicación conjunta al Parlamento Europeo, al Consejo, al Comité Económico y Social Europeo y al Comité de las Regiones: Asociación renovada con los países vecinos meridionales Una nueva Agenda para el Mediterráneo. Esta comunicación propone una renovación de la asociación con los países mediterráneos meridionales 25 años después de la Declaración de Barcelona en constatar los retos regionales que enfrentan los países de ambas ribas. Concretamente algunos de los retos a los que hace referencia es la emergencia 
climática y el deterioro medioambiental, con lo que una de los cinco ámbitos de actuación en los que defiende que se debería basar la nueva estrategia son la resiliencia climática, el medio ambiente y la energía.

En tercer lugar, se emitió la Comunicación conjunta al Parlamento Europeo y al Consejo sobre el refuerzo de la contribución de la UE a un multilateralismo basado en normas. A parte de establecer un posicionamiento muy favorable al multilateralismo en términos generales, la comunicación destaca los ámbitos de la protección del medioambiente y la lucha contra el cambio climático como algunos de los que la cooperación mediante organizaciones internacionales multilaterales ha sido más exitosa. Precisamente el medioambiente es uno de los ámbitos en los que el documento considera que la cooperación con estas organizaciones es más eficiente.

\subsection{Medidas de recuperación en el contexto de la pandemia de COVID-19}

Durante el período de tiempo analizado en esta crónica se han aprobado varios actos por tal de atajar la crisis social y económica originada por la pandemia de COVID-19 que, como veremos, han tenido una visión ambiental más bien limitada. Se aprobó el Reglamento (UE) 2020/2094 del Consejo de 14 de diciembre de 2020 por el que se establece un Instrumento de Recuperación de la Unión Europea para apoyar la recuperación tras la crisis de la COVID-19. Este Instrumento se limitó a apuntar como prioridad de financiación la transición hacia una economía neutra.

Más tarde se aprobaría sin aportar ningún criterio ambiental añadido al anterior el Reglamento (UE) 2020/2221 del Parlamento Europeo y del Consejo de 23 de diciembre de 2020 por el que se modifica el Reglamento (UE) n.o 1303/2013 en lo que respecta a los recursos adicionales y las disposiciones de ejecución a fin de prestar asistencia para favorecer la reparación de la crisis en el contexto de la pandemia de COVID-19 y sus consecuencias sociales y para preparar una recuperación verde, digital y resiliente de la economía (REACT UE).

El Reglamento (UE) 2021/240 del Parlamento Europeo y del Consejo de 10 de febrero de 2021 por el que se establece un instrumento de apoyo técnico, por su lado, hace referencia a aspectos como el medio ambiente, la mitigación del cambio climático, la economía circular o la protección de la biodiversidad como ámbitos de aplicación del 
instrumento, pero no las incluye como acciones que pueden recibir ayuda del Instrumento de apoyo técnico.

Por último, se aprobó el Reglamento (UE) 2021/241 del Parlamento Europeo y del Consejo de 12 de febrero de 2021 por el que se establece el Mecanismo de Recuperación y Resiliencia. El elemento más destacable desde el punto de vista de esta crónica es la obligación de que los objetivos del Mecanismo contribuyan a los objetivos climáticos en al menos el $37 \%$ del total de la financiación. Hay que considerarlo un objetivo claramente insuficiente ya que para el resto del presupuesto canalizado a través de este mecanismo no se le exige tal requisito, añadiendo una simple prohibición de no causar daño ambiental significativo. 